\title{
Planned caesarean section versus planned vaginal delivery among women without formal medical indication for planned caesarean section: A retrospective cohort study of short-term complications
}

\author{
Karin Dahlquist ${ }^{1}$, Andrea Stuart ${ }^{2}$, and Kärin Kallén ${ }^{3}$ \\ ${ }^{1}$ Lund University Clinical Sciences \\ ${ }^{2}$ Helsingborgs lasarett \\ ${ }^{3}$ National Board of Health and Welfare
}

May 4, 2021

\begin{abstract}
Objective: To study complications, within six weeks postpartum, after planned caesarean section (CS) compared with planned vaginal delivery, among women without formal indication for caesarean section. Design: Retrospective cohort study. Setting: Swedish national registries. Population: 714326 deliveries, 2008-2017. Methods: The risks of complications were compared between planned caesarean section and planned vaginal delivery among women without formal medical indication for planned CS. Adjusted Risk Ratios (ARR) were obtained using modified Poisson-regression models adjusting for; maternal age, parity, body mass index, smoking, country of birth, and county. Main outcome measure: infections, haemorrhage and thromboembolism. Results: In the planned CS group $(\mathrm{n}=22 \mathrm{855}), 15 \%$ had a postpartum infection compared with $10 \%$ in the planned vaginal group $(\mathrm{n}=691471)(\mathrm{ARR}=1.6 ; 95 \% \mathrm{CI} 1.5-1.6), 8.4 \%$ vs $0.6 \%$ had haemorrhage $>1$ litre $(\mathrm{ARR}=13.4 ; 95 \% \mathrm{CI} 12.7-14.2)$, and $0.08 \%$ vs $0.05 \%$ had a postpartum pulmonary embolism (ARR $=1.7 ; 95 \%$ CI 1.0-2.6). The obtained risk estimates correspond to a Number-Needed-to-Harm estimate of 17, 14, and 3448, respectively. When dividing the infections into subgroups, an increased risk of endometritis (ARR 1.2; 95\%CI 1.1-1.3), wound infection (ARR 2.7 95\% CI 2.4-3.0), urinary tract infections (ARR 1.5 95\%CI 1.3-1.7), and mastitis (ARR 2.0; 1.9-2.2) was found after planned CS. Conclusion: The risks of short-term maternal complications were higher in women delivered by planned CS compared with planned vaginal delivery among women without formal medical indication for planned CS. Funding: Gorthon Foundation. Key words: caesarean section, puerperal infection, haemorrhage, thromboembolism.
\end{abstract}

\section{Hosted file}

Planned caesarean section versus planned vaginal delivery_210416.pdf available at https: //authorea.com/users/411818/articles/520720-planned-caesarean-section-versus-plannedvaginal-delivery-among-women-without-formal-medical-indication-for-planned-caesareansection-a-retrospective-cohort-study-of-short-term-complications

\section{Hosted file}

Table 1to 3.pdf available at https://authorea.com/users/411818/articles/520720-plannedcaesarean-section-versus-planned-vaginal-delivery-among-women-without-formal-medicalindication-for-planned-caesarean-section-a-retrospective-cohort-study-of-short-termcomplications 

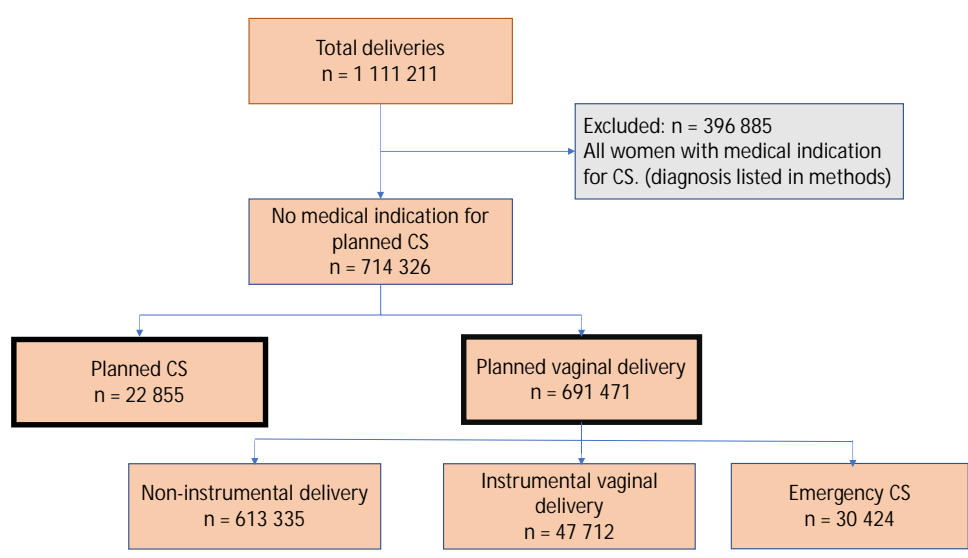